\title{
Cord blood transplantation using minimum conditioning regimens for patients with hematologic malignancies complicated by severe infections
}

Takeshi Yamashita - Chiharu Sugimori - Ken Ishiyama • Hirohito Yamazaki · Hirokazu Okumura •

Yukio Kondo · Akiyoshi Takami · Shinji Nakao

Published online: 24 January 2009

(C) The Japanese Society of Hematology 2009

Erratum to: Int J Hematol

DOI 10.1007/s12185-008-0234-9

Please note that there are errors in this article:

On the 2 nd page on line 14 in the right column, " $13 \mathrm{~h}$ " should be " $23 \mathrm{~h}$ ".

On the 3rd page on line 21 in the left column, " $12 \mathrm{~h}$ " should be " $22 \mathrm{~h}$ ".

The online version of the original article can be found under doi:10.1007/s12185-008-0234-9.

T. Yamashita - C. Sugimori - K. Ishiyama - H. Yamazaki ·

H. Okumura · Y. Kondo · A. Takami · S. Nakao ( $\square)$

Cellular Transplantation Biology,

Kanazawa University Graduate School of Medical Science,

13-1 Takaramachi, Kanazawa 920-8641, Japan

e-mail: snakao@med3.m.kanazawa-u.ac.jp 